Article

\title{
Comparative Assessment of Phenolic Content and in Vitro Antioxidant Capacity in the Pulp and Peel of Mango Cultivars
}

\author{
Arshad Mehmood Abbasi ${ }^{1,2}$, Xinbo Guo ${ }^{1,3, *}$, Xiong Fu ${ }^{1}$, Lin Zhou ${ }^{1,4}$, Youngsheng Chen ${ }^{1}$, \\ Yong Zhu ${ }^{1}$, Huaifeng Yan ${ }^{1}$ and Rui Hai Liu ${ }^{3, *}$
}

1 School of Light Industry and Food Sciences, South China University of Technology, Guangzhou 510641, China; E-Mails: amabbasi@ciit.net.pk (A.M.A.); roger1887@163.com (X.F.); zhoulin@gdpu.edu.cn (L.Z.); chysh11@126.com (Y.C.); zhuyonghappycool@163.com (Y.Z.); jinianjin@outlook.com (H.Y.)

2 Department of Environmental Sciences, COMSATS Institute of Information Technology, Abbottabad 22060, Pakistan

3 Department of Food Science, Cornell University, Ithaca, NY 14850-2824, USA

4 Guangdong Province Key Laboratory for Biotechnology Drug Candidates, School of Biosciences and Biopharmaceutics, Guangdong Pharmaceutical University, Guangzhou 510006, China

* Authors to whom correspondence should be addressed;

E-Mails: r123@cornell.edu (R.H.L.); xbg720@gmail.com (X.G.);

Tel.: +1-607-255-6235 (R.H.L.); +86-20-8711-3848 (X.G.);

Fax: +1-607-255-4868 (R.H.L.); +86-20-8711-3848 (X.G.).

Academic Editor: Maurizio Battino

Received: 8 May 2015 / Accepted: 1 June 2015 /Published: 12 June 2015

\begin{abstract}
Mango (Mangifera indica L.), also called "the king of fruits", is one of the most popular fruits in tropical regions. Pulp and peel samples of mango cultivars were analyzed to estimate total phenolic, total flavonoid and total anthocyanin contents. Phenolic acids, hydrophilic peroxyl radical scavenging capacity (hydro-PSC) and oxygen radical scavenging capacity (ORAC) in vitro were also determined. Total phenolics and flavonoid contents were found maximum in the peel of Xiao Tainang and Da Tainang cultivars, respectively, whereas Xiao Tainang also exhibited significant antioxidant capacity. Noteworthy, concentrations of gallic acid, protocatechuic acid, ferulic acid, chlorogenic acid and caffeic acids at 79.15, 64.33, 33.75, 27.19 and $13.62 \mathrm{mg} / 100 \mathrm{~g}$ fresh weight (FW) were quantified for Da Tainang, Xiao Tainang and of Jidan cultivars, respectively. Comparatively, a higher
\end{abstract}


level of phenolics and significant antioxidant capacity in mango peel indicated that it might be useful as a functional food and value-added ingredient to promote human health.

Keywords: mango; phenolics; flavonoids; anthocyanins; phenolic acids; ORAC; hydro-PSC

\section{Introduction}

Humans have relied on nature throughout the ages for their basic needs of food and health. At present, there is an increasing interest in exploring new sources of plant bio-actives for applications in both the food and pharmaceutical industries [1]. Fruits and vegetables are the most important food sources, which supply essential nutrients and also contain an array of phytochemicals, such as phenolics and flavonoids, to maintain good health [2]. Fruits provide an opportunity for local growers to access the specialized markets where consumers show a preference for exotic characteristics and the presence of nutrients in food, capable of preventing degenerative diseases [3]. A number of reactive oxygen species (ROS), including superoxide anion, hydroxyl and hydrogen peroxide radicals, are produced in the human body by numerous enzymatic systems through oxygen consumption. These reactive oxygen species cause cancer, cardiovascular diseases, aging and neurodegenerative disorders [4]. The ingestion of fruits and vegetables has been connected with a distinguished health-protecting factor against diseases caused by oxidative stress $[5,6]$.

Health benefits of fruits and vegetables have been attributed partly to the compounds having antioxidant capacity and an ability to overcome oxidative stress by neutralizing the overproduction of oxidant species $[7,8]$. It has been reported that the additive and synergistic effects provided by the complex mixture of phytochemicals present in fruits and vegetables cannot be achieved through micronutrient supplements [9]. Polyphenolic compounds, including phenolic acids, xanthones, gallotannins, carotenoids and vitamins ( $\mathrm{E}$ and $\mathrm{C}$ ), are important anti-radical, anti-mutagenic and anti-carcinogen agents $[10,11]$. They reduce the risk of chronic diseases, because of their safety, effectiveness and the presence of hydroxyl groups, which enable these compounds to have more diverse biological activities [12]. Phenolics antioxidants, such as hydroxyl benzoic acid, and their derivatives are potent free radical scavengers of singlet oxygen possibly concerning DNA damage and tumor promotion [13]. Phenolic acids are predominant compounds in the pulp of mango [14]. Consumption of ripened mango is better, as it contains a high content of phenolic acids, which play a significant role in quenching and neutralizing the free radicals to improve consumers' health $[15,16]$. Gallic acid is one the important anticancer agents, particularly against human prostate cancer cells in vitro and in vivo [17]. Ferulic acid is an important phenolic compound in fruits and vegetables, which is generated as a result of phenylalanine and tyrosine metabolism [18]. By virtue of effectively scavenging harmful radicals and suppressing radiation-induced oxidative reactions, ferulic acid serves as an important antioxidant, protects the body against different inflammatory diseases and is essential in preserving the physiological integrity of cells exposed to both air and impinging UV radiation [19]. In vitro and in vivo studies have revealed that chlorogenic acid is one of the most abundant polyphenols in the human diet, which exhibits significant anti-edematogenic, anti-nociceptive, antioxidant and anti-carcinogenic activities [20]. It has been reported that protocatechuic acid showed anti-proliferative activity against 
HL-60 cells by inducing apoptosis and is associated with the phosphorylation and suppression of Bcl-2 protein [21]. Caffeic acid has been proven as an inhibitor of hypertension and cardiotoxicity in rats by enhanced blood pressure, cardiac injury markers, restoration of the oxidant/antioxidant status, as well as decreasing histopathological changes [22].

Mangifera indica L. (mango), "the king of fruits" belonging to the family Anacardiaceae, is one of the most popular fruits in tropical regions. Mango has been cultivated for 4000 years and ranks only second to pineapple in quantity and value among internationally-traded tropical fruits. In Mainland China, mango was first introduced from India in 645 A.D. by Tang Xuangzang (Tang Dynasty), and its commercial cultivation was started in the 1980s. Now, China has become the seventh mango cultivation country in the world, with annual production of about 1,061,800 tones on 133,100 hectares [23]. Mango is considered as a good source of dietary compounds, such as ascorbic acid, phenolic compounds and carotenoids [15,24,25], which are beneficial to health due to their antioxidant capacity [26,27]. The pulp of mango is effective for leukemia, prostate, breast and colon cancers in vitro. Peels are the major by-products of different fruits and are good sources of phytochemicals and bioactive compounds [28-30]. Mango peel, which comprises $15 \%-20 \%$ of the fruit, is an edible tissue and a major by-product of the mango processing industry. Peel of unripe mango is used in making chutney and pickle, while that of the ripe fruit, due to its leathery nature, is not so satisfactory in taste, therefore being generally removed and discarded. In the food processing industry, mango peel is removed for technological and sensory advantages and usually ends up as a waste by-product [31]. Mango peel has been found to be a good source of polyphenols, carotenoids, dietary fiber, vitamin $\mathrm{E}$ and vitamin $\mathrm{C}[28,31]$, and it showed significant antioxidant properties [32,33].

Total phenolics, vitamin $\mathrm{C}$ and antioxidant activity have been reported in the fruit of mango varieties $[15,24,25]$. However, comparative assessment of total phenolic content, phenolic acids and in vitro antioxidant capacity in the pulp and peel of mango cultivars predominantly cultivated in China has rarely been reported before. In this context, the present study was designed to evaluate and correlate phenolic content and antioxidant activity and to assess the disparity in phenolic compounds and antioxidant capacity in the pulp and peel of nine cultivars of mango.

\section{Results and Discussion}

\subsection{Moisture Content}

Moisture levels as the percentage of moisture content determined in the pulp and peel of mango cultivars are given in Table 1. Overall, pulp samples contain higher moisture content than peel. Interestingly, maximum moisture content was determined in the pulp and peel of the Kaite cultivar at $89.47 \%$ and $87.04 \%$, respectively. The Da Tainang cultivar showed the lowest level of moisture at 81.68 for pulp and 77.57 for peel sample. In the present study, the percentage of moisture content of the peel samples was higher than reported previously for Raspuri and Badami mango varieties (65\%-75\%) from India [32], which might be due to genetic variation and climatic conditions. 
Table 1. Descriptions of the mango cultivars and the percentage of moisture content.

\begin{tabular}{ccccccc}
\hline \multirow{2}{*}{ Variety } & \multicolumn{2}{c}{ Abbreviation } & \multirow{2}{*}{ Color } & & \multicolumn{2}{c}{ \% Moisture Content } \\
\cline { 2 - 3 } & Pulp & Peel & & & Pulp & Peel \\
\hline Luzon mango (Lvsong) & F1 & P1 & Greenish yellow & $85.13^{\mathrm{ab}} \pm 0.70$ & $82.21^{\mathrm{c}} \pm 0.53$ \\
Narcissus mango (Shuixian) & F2 & P2 & Yellow & & $80.69^{\mathrm{c}} \pm 0.92$ & $79.18^{\mathrm{e}} \pm 0.09$ \\
Royal mango (Guifei) & F3 & P3 & Yellowish red & $88.53^{\mathrm{a}} \pm 0.32$ & $83.49^{\mathrm{b}} \pm 0.55$ \\
Big Tainong mango (Da Tainang) & F4 & P4 & Yellow & $81.68^{\mathrm{bc}} \pm 0.55$ & $77.57^{\mathrm{f}} \pm 0.31$ \\
Keitt mango (Kaite) & F5 & P5 & Green & $89.47^{\mathrm{a}} \pm 4.65$ & $87.04^{\mathrm{a}} \pm 0.50$ \\
Australian mango (Aozhou) & F6 & P6 & Reddish yellow & $85.89^{\mathrm{a}} \pm 0.21$ & $83.90^{\mathrm{b}} \pm 0.13$ \\
Thai mango (Xiangya) & F7 & P7 & Green & $86.01^{\mathrm{a}} \pm 0.38$ & $81.66^{\mathrm{cd}} \pm 0.71$ \\
Small Tainong mango (Xiao Tainang) & F8 & P8 & Yellow & $88.80^{\mathrm{a}} \pm 0.10$ & $81.01^{\mathrm{d}} \pm 0.42$ \\
Egg mango (Jidan) & F9 & P9 & Yellow greenish & $87.87^{\mathrm{a}} \pm 0.13$ & $84.25^{\mathrm{b}} \pm 0.44$ \\
\hline
\end{tabular}

Values are the means of three replicates $\pm \mathrm{SD}$. Different letters $(\mathrm{a}-\mathrm{f})$ within the columns indicate significant difference at $p<0.05$.

\subsection{Total Phenolic Content}

Phenolics are among the major contributors that are accountable for antioxidant properties in fruits, vegetables, whole grains and other plant-based materials [34]. Although total phenolic compounds in the mango pulp have been reported before, to our knowledge, the phenolic composition in the peel of Chinese cultivars is estimated for the first time here. The measured levels of total phenolic content (TPC) in the pulp and peel samples of mango cultivars are presented in Table 2, which indicated that peel samples contained high phenolic content compared to pulp. Our results are consistent with a previous report [35] that peel always contains more phenolic contents than pulp at any stage of mango fruit.

Peel is an important by-product of mango processing and is a good source of high-quality pectin and polyphenols [36]. On the whole, the peel and pulp of the Xiao Tainang cultivar exhibited a higher concentration of total phenolics among all of the studied samples. In peel samples, TPC ranged from 462.2-4071 $\mathrm{mg}$ gallic acid equivalent (GAE)/100 $\mathrm{g}$ fresh weight (FW). The Lvsong cultivar contained the lowest level of total phenolics, while in the peel of the Xiao Tainang variety, the TPC level was highest with a significant difference $(p<0.05)$. It was noted that the total phenolic contents reported in the peel of Pica mango from Chile [24] and the Ataulfo variety from Mexico [37] were slightly higher than the present results. Differences in the cultivars, their origins and genetic variation might result in the inconsistency among the findings [38].

In the pulp samples, the maximum concentration of TPC was estimated for Xiao Tainang at $97.47 \mathrm{mg}$ GAE/100 g FW, followed by Aozhou, Da Tainang and Shuixian cultivars, while Lvsong showed the lowest content. The measured levels of total phenolic content in the pulp samples were in agreement, as reported earlier in different varieties of mango, such as Tommy Atkins and Pica mango from the USA and Chile [24-27], as well as in Brazil and Ecuador [37] and the Haden variety from Mexico [39]. 
Table 2. Total phenolics, flavonoids and anthocyanins contents of mango pulp and peel.

\begin{tabular}{ccccccc}
\hline \multirow{2}{*}{ Varieties } & \multicolumn{2}{c}{ Total Phenolics Content } & \multicolumn{2}{c}{ Total Flavonoids Content } & \multicolumn{2}{c}{ Total Anthocyanins Content } \\
\cline { 2 - 7 } & Pulp & Peel & Pulp & Peel & Pulp & Peel \\
\hline F1 & $22.06^{\mathrm{g}} \pm 0.27$ & $462.2^{\mathrm{h}} \pm 10.06$ & $3.069^{\mathrm{fg}} \pm 0.21$ & $34.61^{\mathrm{d}} \pm 1.29$ & nd & $0.006^{\mathrm{b}} \pm 0.01$ \\
F2 & $62.45^{\mathrm{d}} \pm 1.25$ & $622.4^{\mathrm{g}} \pm 4.46$ & $8.321^{\mathrm{b}} \pm 0.15$ & $48.87^{\mathrm{c}} \pm 1.50$ & nd & nd \\
F3 & $48.77^{\mathrm{e}} \pm 0.34$ & $997.9^{\mathrm{e}} \pm 19.61$ & $2.995^{\mathrm{fg}} \pm 0.15$ & $29.85^{\mathrm{e}} \pm 1.18$ & $0.0005^{\mathrm{a}} \pm 0.0$ & $0.659^{\mathrm{a}} \pm 0.01$ \\
F4 & $74.41^{\mathrm{c}} \pm 3.00$ & $2805^{\mathrm{b}} \pm 17.42$ & $4.578^{\mathrm{d}} \pm 0.15$ & $75.35^{\mathrm{a}} \pm 2.68$ & nd & $0.049^{\mathrm{b}} \pm 0.01$ \\
F5 & $28.14^{\mathrm{f}} \pm 0.91$ & $927.2^{\mathrm{f}} \pm 17.07$ & $0.904^{\mathrm{i}} \pm 0.07$ & $19.91^{\mathrm{f}} \pm 0.70$ & nd & nd \\
F6 & $83.49^{\mathrm{b}} \pm 2.07$ & $1131^{\mathrm{d}} \pm 12.87$ & $9.252^{\mathrm{a}} \pm 0.18$ & $59.31^{\mathrm{b}} \pm 3.71$ & $0.0001^{\mathrm{a}} \pm 0.0$ & $0.647^{\mathrm{a}} \pm 0.07$ \\
F7 & $45.78^{\mathrm{e}} \pm 0.67$ & $1376^{\mathrm{c}} \pm 15.22$ & $2.583^{\mathrm{h}} \pm 0.54$ & $19.91^{\mathrm{f}} \pm 0.59$ & $0.0004^{\mathrm{a}} \pm 0.0$ & $\mathrm{nd}$ \\
F8 & $97.47^{\mathrm{a}} \pm 6.76$ & $4071^{\mathrm{a}} \pm 17.47$ & $5.735^{\mathrm{c}} \pm 0.45$ & $59.20^{\mathrm{b}} \pm 1.89$ & nd & $0.014^{\mathrm{b}} \pm 0.03$ \\
F9 & $51.68^{\mathrm{e}} \pm 0.66$ & $1145^{\mathrm{d}} \pm 15.07$ & $3.500^{\mathrm{e}} \pm 0.20$ & $27.49^{\mathrm{e}} \pm 0.88$ & nd & $0.015^{\mathrm{b}} \pm 0.02$ \\
\hline
\end{tabular}

Phenolic content expressed as mg of gallic acid equivalents per $100 \mathrm{~g}$ of fresh weight (FW); flavonoid content expressed as $\mathrm{mg}$ of catechin equivalents per $100 \mathrm{~g}$ of $\mathrm{FW}$; anthocyanin content expressed as $\mathrm{mg} / 100 \mathrm{~mL}$ of cyanidin 3-glucoside equivalents on a fresh weight basis; nd, not detected; different letters (a-i) within the columns indicate significant difference at $p<0.05$; values are the means of three replicates $\pm \mathrm{SD}$.

\subsection{Total Flavonoid Content}

Estimated values of total flavonoid content (TFC) in the studied samples are given in Table 2, which revealed that peel samples exhibited a significant level of TFC compared to the pulp samples. These findings were in agreement that in mango, the peel contains more flavonoids than pulp [15]. In the peel samples, TFC ranged between 75.35-19.90 mg catechin equivalent (CE)/100 g FW. The peel of the Da Tainang cultivar showed the highest content of total flavonoids at $75.35 \mathrm{mg} \mathrm{CE} / 100 \mathrm{~g} \mathrm{FW}$, whereas the lowest values were calculated in the Kaite and Xiangya cultivars. These concentrations were statistically different $(p<0.05)$ among the studied samples. In the case of pulp samples, the concentration of total flavonoids was maximum in Aozhou (9.252 mg CE/100 g FW), whereas the minimum content was estimated for the Kaite variety at $0.904 \mathrm{mg} \mathrm{CE} / 100 \mathrm{~g} \mathrm{FW}$. Our results demonstrated that the measured levels of total flavonoid content were comparatively higher than reported previous reports for the pulp and peel of Pica variety from Chile [24], for the pulp of Mallika variety from China [25] and Ataulfo mango [15,40].

\subsection{Total Anthocyanin Contents}

Anthocyanins are well known because of their antioxidant properties and their pigmenting power that make them attractive to be used as food colorants [1,32]. It has been reported that anthocyanins are comparatively higher in ripe mango peel than raw peel [32]. Like phenolic and flavonoid contents, total anthocyanin content (TAC) was also estimated to be more in the peel samples than pulp (Table 2). In the peel samples, the maximum contents of total anthocyanins were determined in the Guifei and Aozhou cultivars at 0.659 and $0.647 \mathrm{mg} / 100 \mathrm{~mL}$ of cyanidin 3-glucoside equivalents on a fresh weight basis, respectively. However, the contents of total anthocyanins in the pulp samples were very low. Anthocyanin contents were below the detection limit in the peel of Shuixian, Kaite and Xiangya and in the pulp of Lvsong, Shuixian, Da Tainang, Kaite, Xiao Tainang and Jidan. Compared to the literature, the present findings indicated that anthocyanin contents in Chinese cultivars were comparatively lower 
than reported in the peel of Indian mango [32], which might be attributed to genetic variation and their origin. Likewise, the reported level of TAC (2.1-26.8 mg of cyanidin 3-glucoside equivalent/100 g) in the peel of apple [41] was significantly higher than mango peel. In general, the present analysis revealed that mango peel contains more contents of total phenolics, flavonoids and anthocyanins. Therefore, it could be an excellent source of natural antioxidants and bioactive ingredients of functional food.

\subsection{Phenolic Acids Composition}

Measured levels of gallic acid, caffeic acid, chlorogenic acid, protocatechuic acid, vanillic acid and $p$-coumaric acid, which were identified and quantified for the first time by the HPLC method in the pulp and peel of different mango cultivars grow in China, are presented in Tables 3 and 4. Comparatively, elevated levels of phenolic acids were determined in the peel samples. Though similar types of phenolic acids have been reported before in different varieties of mango [10,15,36], in the case of pulp, concentrations of phenolic acids were different than reported for Ataulfo [15,40], Kent [14] and Tommy Atkins [34] varieties of mango. Gallic acid, caffeic acid, chlorogenic acid and protocatechuic acid were identified in all studied samples (Figure 1A,B). Ferulic and vanillic acids were determined only in the pulp samples (Figure 1A), while $p$-coumaric acid was estimated in the peel samples only (Figure 1B). In the pulp samples, ferulic acid was predominant, followed by protocatechuic, chlorogenic, gallic, vanillic and caffeic acids. However, in the peel samples, gallic acid was predominant, followed by protocatechuic acid, chlorogenic acid, caffeic acid and $p$-coumaric acid. The Xiao Tainang cultivar exhibited the highest content of ferulic acid $(33.75 \mathrm{mg} / 100 \mathrm{~g})$ on a fresh weight basis, followed by Aozhou and Guifei. The lowest concentration of ferulic acid was present in the pulp of Lvsong, whereas in the Da Tainang and Kaite, cultivars ferulic acid contents were below the detection limit.

In the peel samples, the gallic acid concentration varied from $79.15-1.450 \mathrm{mg} / 100 \mathrm{~g} \mathrm{FW}$. Gallic acid was maximum in the peel of the Da Tainang cultivar, whereas the minimum content was determined in Aozhou. In the pulp samples, the highest content of gallic acid was estimated for Aozhou, followed by the Lvsong and Da Tainang cultivars at 2.982, 2.492 and $2.369 \mathrm{mg} / 100 \mathrm{~g} \mathrm{FW}$, respectively. These values were significantly different at $p<0.05$. In the peel samples, measured values of gallic acid were compatible with the reported levels in the Ataulfo variety, whereas pulp contained a lower concentration than the reported levels in previous studies [15]. It was noted that, in the peel of the Jidan cultivar, chlorogenic acid was maximum at $27.19 \mathrm{mg} / 100 \mathrm{~g} \mathrm{FW}$, whereas the lowest value was estimated in the peel of Shuixian. However, in the pulp samples, chlorogenic acid ranged from $0.957 \mathrm{mg} / 100 \mathrm{~g} \mathrm{FW}$ in Xiangya to $6.147 \mathrm{mg} / 100 \mathrm{~g} \mathrm{FW}$ in the Aozhou cultivar, and these values were considerably lower compared to Ataulfo mango [15].

A significant level of protocatechuic acid was quantified in the peel of Xiao Tainang at $64.33 \mathrm{mg} / 100 \mathrm{~g} \mathrm{FW}$, followed by the Aozhou and Jidan cultivars with a significant difference at $p<0.05$. In the case of pulp samples, the maximum concentration of protocatechuic acid was estimated in the pulp of Aozhou, followed by the Jidan and Xiao Tainang cultivars. In the pulp samples, caffeic acid ranged between 1.117 and $0.250 \mathrm{mg} / 100 \mathrm{~g} \mathrm{FW}$. The highest concentration of caffeic acid was determined in the peel of Jidan at $13.62 \mathrm{mg} / 100 \mathrm{~g} \mathrm{FW}$, followed by Xiangya and Xiao Tainang at 7.070 and $2.989 \mathrm{mg} / 100 \mathrm{~g} \mathrm{FW}$, respectively, whereas it was undetectable in the peel of other cultivars. 

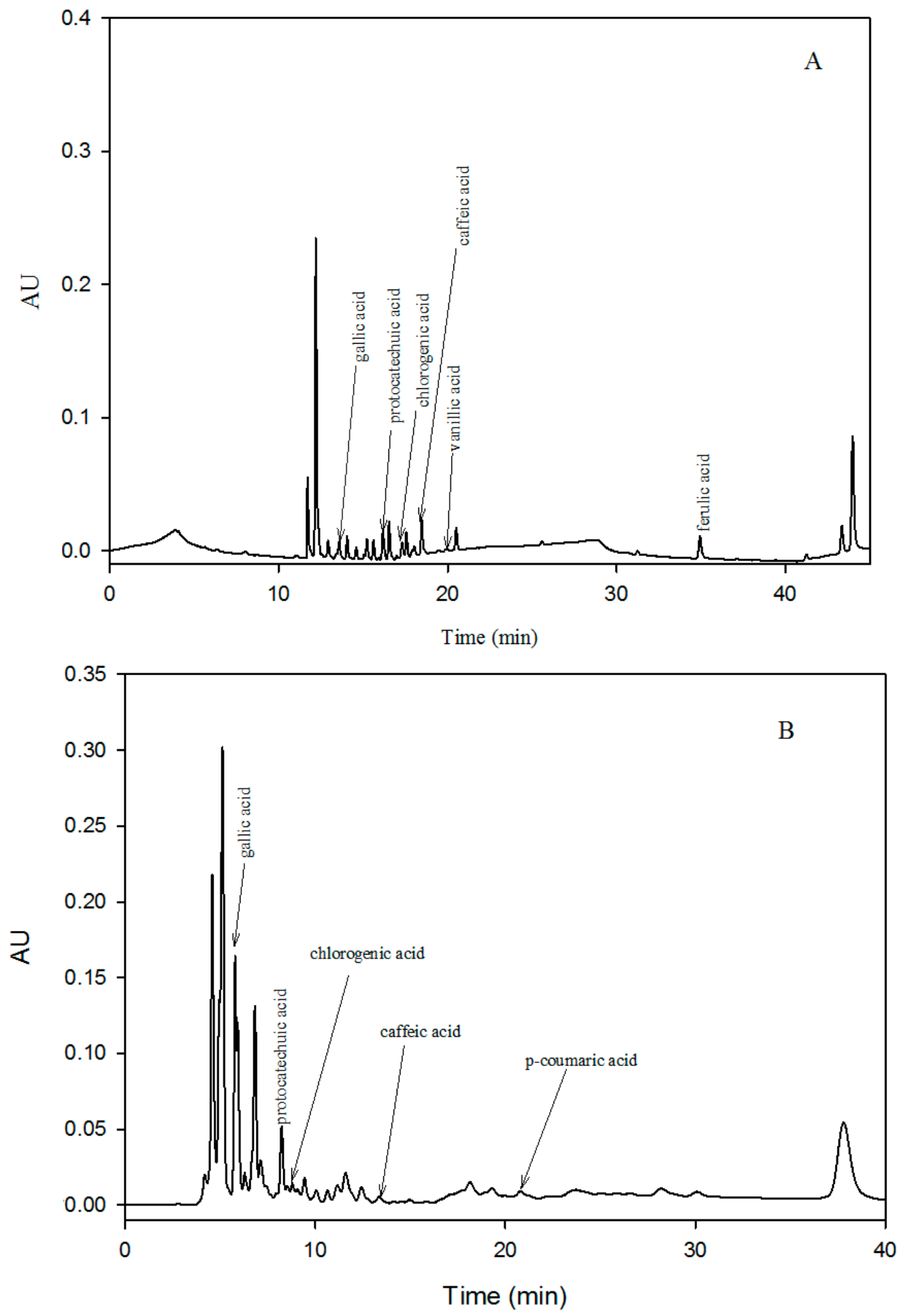

Figure 1. (A) HPLC-chromatogram showing the phenolic acid composition in the pulp samples of mango recorded at 280 and $320 \mathrm{~nm}$; and (B) HPLC-chromatogram showing the phenolic acid composition in the peel samples of mango recorded at 280 and $320 \mathrm{~nm}$. 
Table 3. Phenolic acids content $(\mathrm{mg} / 100 \mathrm{~g} \mathrm{FW})$ in the pulp samples of mango cultivars.

\begin{tabular}{ccccccc}
\hline Varieties & Gallic Acid & Caffeic Acid & Protocatechuic Acid & Chlorogenic Acid & Vanillic Acid & Ferulic Acid \\
\hline F1 & $2.492^{\mathrm{ab}} \pm 0.11$ & $0.562^{\mathrm{a}} \pm 0.03$ & $1.234^{\mathrm{cde}} \pm 0.084$ & $1.589^{\mathrm{c}} \pm 0.148$ & $0.642^{\mathrm{de}} \pm 0.032$ & $1.206^{\mathrm{e}} \pm 0.21$ \\
F2 & $1.543^{\mathrm{bc}} \pm 0.15$ & $0.264^{\mathrm{a}} \pm 0.04$ & $1.116^{\mathrm{de}} \pm 0.073$ & $3.779^{\mathrm{b}} \pm 0.167$ & $1.042^{\mathrm{b}} \pm 0.069$ & $20.31^{\mathrm{bc}} \pm 1.15$ \\
$\mathrm{~F} 3$ & $2.359^{\mathrm{ab}} \pm 0.08$ & $0.485^{\mathrm{a}} \pm 0.10$ & $0.767^{\mathrm{e}} \pm 0.011$ & $1.298^{\mathrm{cd}} \pm 0.051$ & $0.669^{\mathrm{de}} \pm 0.125$ & $28.69^{\mathrm{ab}} \pm 2.14$ \\
$\mathrm{~F} 4$ & $2.369^{\mathrm{ab}} \pm 0.41$ & $0.707^{\mathrm{a}} \pm 0.15$ & $1.768^{\mathrm{bcd}} \pm 0.033$ & $1.040^{\mathrm{d}} \pm 0.065$ & $0.900^{\mathrm{bc}} \pm 0.079$ & $\mathrm{nd}$ \\
$\mathrm{F} 5$ & $1.788^{\mathrm{bc}} \pm 1.02$ & $0.767^{\mathrm{a}} \pm 0.33$ & $0.984^{\mathrm{de}} \pm 0.042$ & $0.971^{\mathrm{d}} \pm 0.021$ & $0.802^{\mathrm{cd}} \pm 0.026$ & $\mathrm{nd}$ \\
F6 & $2.982^{\mathrm{a}} \pm 0.23$ & $1.117^{\mathrm{a}} \pm 0.10$ & $6.826^{\mathrm{a}} \pm 0.532$ & $6.147^{\mathrm{a}} \pm 0.407$ & $1.625^{\mathrm{a}} \pm 0.095$ & $28.96^{\mathrm{ab}} \pm 2.83$ \\
F7 & $0.927^{\mathrm{c}} \pm 0.08$ & $0.250^{\mathrm{a}} \pm 0.04$ & $1.211^{\mathrm{cde}} \pm 0.078$ & $0.957^{\mathrm{d}} \pm 0.061$ & $0.565^{\mathrm{d}} \pm 0.090$ & $7.207^{\mathrm{de}} \pm 3.47$ \\
F8 & $2.168^{\mathrm{ab}} \pm 0.25$ & $0.894^{\mathrm{a}} \pm 0.09$ & $2.046^{\mathrm{bc}} \pm 0.044$ & $1.246^{\mathrm{cd}} \pm 0.103$ & $1.461^{\mathrm{a}} \pm 0.101$ & $33.75^{\mathrm{a}} \pm 1.44$ \\
F9 & $2.112^{\mathrm{ab}} \pm 0.06$ & $0.481^{\mathrm{a}} \pm 0.04$ & $2.288^{\mathrm{b}} \pm 0.116$ & $1.335^{\mathrm{cd}} \pm 0.035$ & $0.942^{\mathrm{bc}} \pm 0.017$ & $15.48^{\mathrm{cd}} \pm 5.97$ \\
\hline
\end{tabular}

Different letters (a-e) within the columns indicate significant difference at $p<0.05$; values are the means of three replicates \pm SD; nd.: not detected.

Table 4. Phenolic acids content (mg/100 g FW) in the peel samples of mango cultivars.

\begin{tabular}{cccccc}
\hline Varieties & Gallic Acid & Caffeic Acid & Protocatechuic Acid & Chlorogenic Acid & $\boldsymbol{p}$-Coumaric Acid \\
\hline P1 & $7.376^{\mathrm{b}} \pm 1.01$ & nd & $8.396^{\mathrm{b}} \pm 1.57$ & $4.523^{\mathrm{a}} \pm 0.77$ & $\mathrm{nd}$ \\
P2 & $2.710^{\mathrm{b}} \pm 2.35$ & nd & $3.167^{\mathrm{b}} \pm 0.25$ & $4.405^{\mathrm{a}} \pm 0.08$ & $\mathrm{nd}$ \\
P3 & $21.38^{\mathrm{b}} \pm 1.15$ & nd & $3.989^{\mathrm{b}} \pm 0.32$ & $4.462^{\mathrm{a}} \pm 0.30$ & nd \\
P4 & $79.15^{\mathrm{a}} \pm 8.61$ & nd & $7.807^{\mathrm{b}} \pm 1.63$ & $9.409^{\mathrm{a}} \pm 1.16$ & $0.291^{\mathrm{a}} \pm 0.50$ \\
P5 & $16.57^{\mathrm{b}} \pm 3.82$ & nd & $3.077^{\mathrm{b}} \pm 0.51$ & $5.944^{\mathrm{a}} \pm 0.04$ & $\mathrm{nd}$ \\
P6 & $1.450^{\mathrm{b}} \pm 1.27$ & nd & $35.23^{\mathrm{ab}} \pm 9.10$ & $19.65^{\mathrm{a}} \pm 1.50$ & $\mathrm{nd}$ \\
P7 & $10.83^{\mathrm{b}} \pm 2.42$ & $3.303^{\mathrm{b}} \pm 0.683$ & $2.974^{\mathrm{b}} \pm 0.20$ & $25.37^{\mathrm{a}} \pm 2.70$ & $\mathrm{nd}$ \\
P8 & $6.672^{\mathrm{b}} \pm 1.78$ & $4.484^{\mathrm{b}} \pm 0.105$ & $64.33^{\mathrm{a}} \pm 14.4$ & $21.96^{\mathrm{a}} \pm 2.14$ & $0.676^{\mathrm{a}} \pm 0.61$ \\
P9 & $1.834^{\mathrm{b}} \pm 1.59$ & $14.43^{\mathrm{a}} \pm 2.97$ & $12.63^{\mathrm{b}} \pm 2.18$ & $27.19^{\mathrm{a}} \pm 3.02$ & nd \\
\hline
\end{tabular}

Different letters (a,b) within the columns indicate significant difference at $p<0.05$; values are the means of three replicates \pm SD; nd.: not detected. 


\subsection{Antioxidant Capacity}

The results of in vitro antioxidant capacity determined PSC and ORAC assays are presented in Figures 2 and 3. In general, peel samples showed more antioxidant capacity compared to pulp. The hydro-PSC method was used for the first time to evaluate the antioxidant capacity of mango. In the peel samples, the PSC values ranged between 61.91 and $10.25 \mu \mathrm{M}$ vitamin $\mathrm{C}$ equivalent/g FW. The highest peroxyl radical scavenging capacity was shown by the Aozhou cultivar, followed by Xiao Tainang and Da Tainang, whereas Lvsong showed the lowest level (Figure 2B). In the pulp samples, the maximum PSC value was calculated for the Xiao Tainang cultivar at $8.713 \mu \mathrm{M}$ vitamin $\mathrm{C}$ equivalent/g FW (Figure 2A).

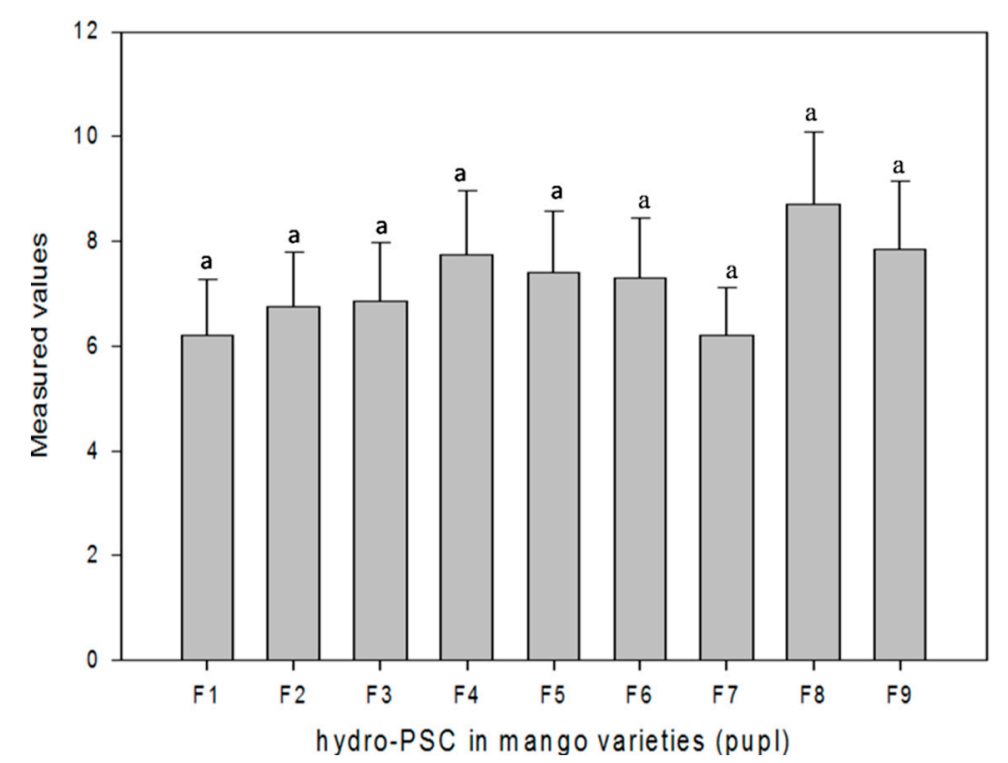

(A)

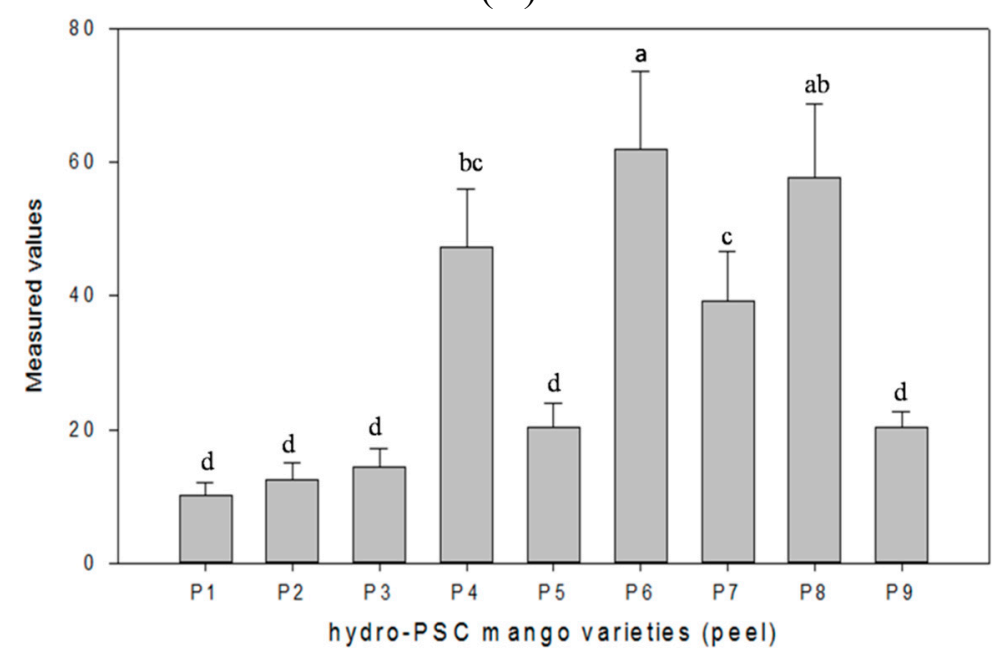

(B)

Figure 2. (A) Hydro-PSC values ( $\mu \mathrm{M}$ vitamin $\mathrm{C}$ equivalent/g FW) in pulp samples; the means of three replicates $\pm \mathrm{SD}$; letters "a" indicate significant difference at $p<0.05$; (B) Hydro-PSC values ( $\mu \mathrm{M}$ vitamin $\mathrm{C}$ equivalent/g FW) in peel samples, the means of three replicates $\pm \mathrm{SD}$; different letters "a-d" indicate significant difference at $p<0.05$. 
The results of oxygen radical absorbance capacity (ORAC) indicated that peel and pulp of the Xiao Tainang cultivar showed antioxidant capacity determined by the ORAC assay at 549.8 and $29.50 \mu \mathrm{M}$ Trolox equivalent/g FW (Figure 3A,B) among all of the studied samples. In the previous studies, the antioxidant activity of mango has been estimated by different methods [15,24-27,32], which are incomparable to our findings. However, it was noted that measured values of oxygen radical absorbance capacity in mango pulp were compatible to [25,27]. To our knowledge, mango peel has never been analyzed to determine the oxygen radical absorbance capacity before.

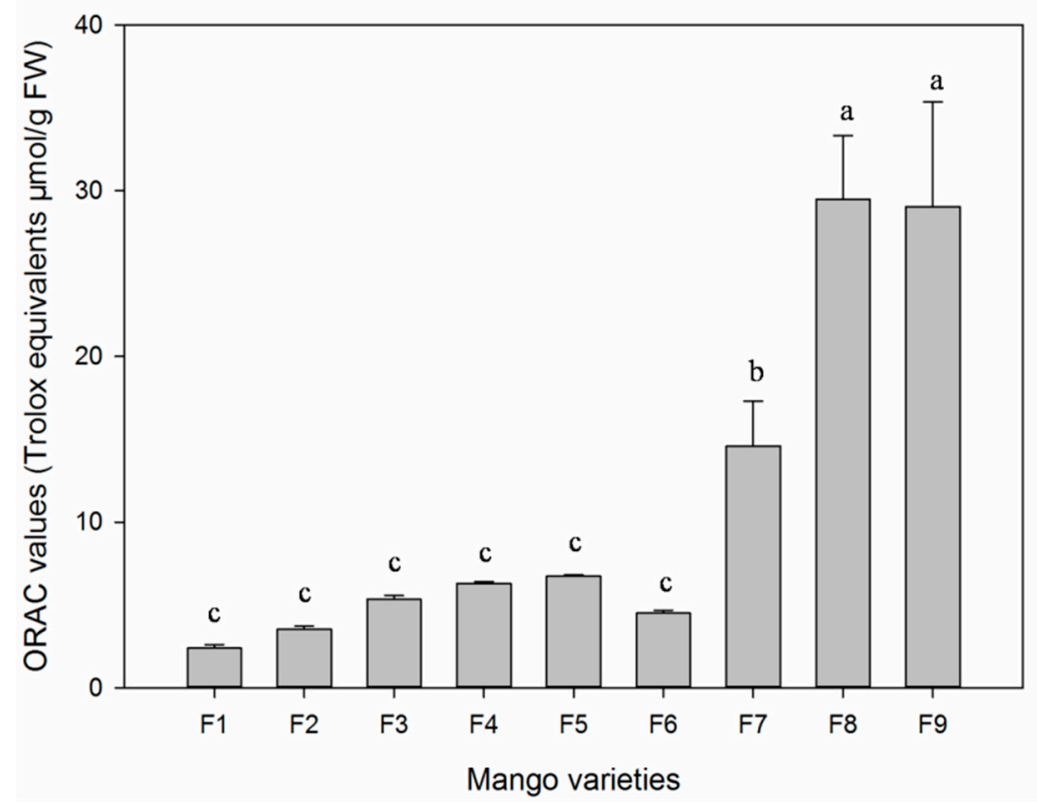

(A)

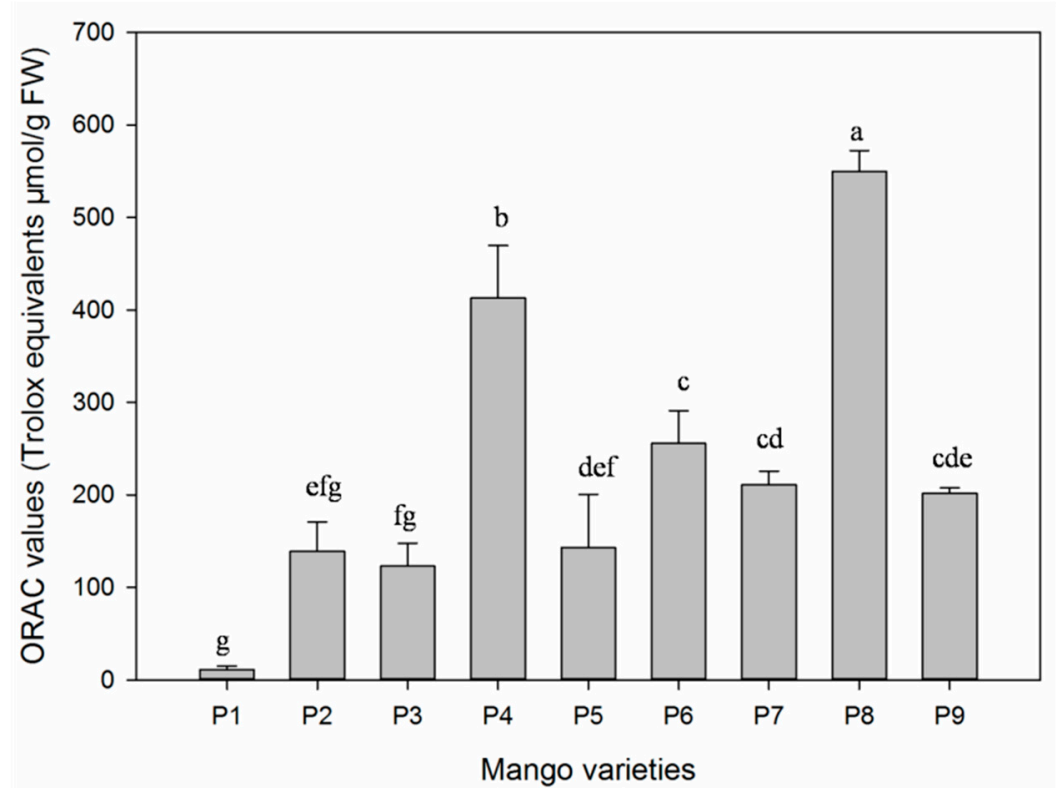

(B)

Figure 3. (A) ORAC value in pulp samples, the means of three replicates $\pm \mathrm{SD}$; different letters "a-c" indicate significant difference at $p<0.05$; (B) ORAC value in peel samples; the means of three replicates $\pm \mathrm{SD}$; different letters "a-g" indicate significant difference at $p<0.05$. 
Table 5. Correlation coefficient matrix between phenolics content and antioxidant properties in mango pulp.

\begin{tabular}{|c|c|c|c|c|c|c|c|c|c|c|c|}
\hline & TPC & TFC & TAC & GA & $\mathbf{C A}$ & $\mathbf{P A}$ & CIA & VA & FA & PSC & ORAC \\
\hline TPC & 1.000 & & & & & & & & & & \\
\hline TFC & $0.714 *$ & 1.000 & & & & & & & & & \\
\hline TAC & -0.964 & -0.968 & 1.000 & & & & & & & & \\
\hline GA & 0.287 & 0.349 & -0.586 & 1.000 & & & & & & & \\
\hline $\mathrm{CA}$ & 0.485 & 0.310 & -0.895 & $0.735 *$ & 1.000 & & & & & & \\
\hline PA & 0.520 & 0.661 & -0.994 & 0.577 & $0.694 *$ & 1.000 & & & & & \\
\hline $\mathrm{ClA}$ & 0.390 & $0.858 * *$ & -0.967 & 0.420 & 0.391 & $\mathbf{0 . 8 0 7} * *$ & 1.000 & & & & \\
\hline VA & $0.822 * *$ & $0.784 *$ & -0.959 & 0.499 & $0.736 *$ & $0.766 *$ & $0.676 *$ & 1.000 & & & \\
\hline FA & 0.663 & 0.591 & -0.330 & 0.287 & 0.273 & 0.402 & 0.453 & 0.653 & 1.000 & & \\
\hline PSC & $0.675 *$ & 0.172 & -0.659 & 0.313 & 0.580 & 0.210 & -0.088 & 0.635 & 0.378 & 1.000 & \\
\hline ORAC & 0.368 & -0.109 & 0.383 & -0.177 & 0.038 & -0.013 & -0.352 & 0.253 & 0.319 & 0.648 & 1.000 \\
\hline
\end{tabular}

TPC, Total phenolic content; TFC, Total flavonoid content; TAC, Total anthocyanin content; GA, Gallic acid; CA, Caffeic acid; PCA, Protocatechuic acid; ClA, Chlorogenic acid; VA, Vanillic acid; FA, Ferulic acid; PSC, Peroxyl radical scavenging capacity; ORAC, Oxygen radical absorbance capacity; * Correlation is significant at the 0.05 level (2-tailed); ** Correlation is significant at the 0.01 level (2-tailed).

Table 6. Correlation coefficient matrix between phenolics content and antioxidant properties in mango peel.

\begin{tabular}{|c|c|c|c|c|c|c|c|c|c|c|}
\hline & TPC & TFC & TAC & GA & $\mathbf{C A}$ & PCA & ClA & $p \mathrm{CA}$ & PSC & ORAC \\
\hline TPC & 1.000 & & & & & & & & & \\
\hline TFC & 0.589 & 1.000 & & & & & & & & \\
\hline TAC & -0.380 & -0.095 & 1.000 & & & & & & & \\
\hline GA & 0.379 & 0.492 & -0.168 & 1.000 & & & & & & \\
\hline $\mathrm{CA}$ & 0.042 & -0.387 & -0.405 & -0.287 & 1.000 & & & & & \\
\hline PCA & $0.723 *$ & 0.491 & -0.097 & -0.237 & 0.016 & 1.000 & & & & \\
\hline $\mathrm{ClA}$ & 0.372 & -0.041 & -0.211 & -0.282 & $0.786 *$ & 0.463 & 1.000 & & & \\
\hline$p \mathrm{CA}$ & $0.962 * *$ & 0.585 & -0.441 & 0.254 & -0.059 & $0.782 *$ & 0.241 & 1.000 & & \\
\hline PSC & $0.702 *$ & 0.615 & 0.106 & 0.192 & -0.025 & $0.713 *$ & 0.564 & 0.587 & 1.000 & \\
\hline ORAC & $\mathbf{0 . 9 7 7} * *$ & 0.655 & -0.332 & 0.356 & 0.048 & $\mathbf{0 . 7 5 3} *$ & 0.441 & $0.920 * *$ & $0.805 * *$ & 1.000 \\
\hline
\end{tabular}

TPC, Total phenolic content; TFA, Total flavonoid content; TAC, Total anthocyanin content; GA, Gallic acid; CA, Caffeic acid; PCA, Protocatechuic acid; ClA, Chlorogenic acid; $p$ CA, $p$-Coumaric acid; PSC, Peroxyl radical scavenging capacity; ORAC, Oxygen radical absorbance capacity; * Correlation is significant at the 0.05 level (2-tailed); ** Correlation is significant at the 0.01 level (2-tailed). 


\subsection{Correlations}

In view of the fact that a large number of different antioxidants contribute to the total antioxidant capacity, it is not yet clear which components are more accountable for the observed antioxidant capacity [26]. Significant correlations between phenolic compounds and antioxidant activity in various kinds of fruits have been reported in previous studies [2,42-44]. Tables 5 and 6 showed correlation coefficient matrices between phenolic content (i.e., TPC, TFC, TAC and phenolic acids) and antioxidant capacity in the pulp and peel samples. In the peel samples, highly significant coefficients of determination were calculated between TPC-ORAC, TPC- $p$-coumaric acid, ORAC- $p$-coumaric acid and ORAC-PSC (0.977, 0.962, 0.920 and 0.805, respectively). In the pulp samples, significant correlations were noted between TFC and chlorogenic acid $(r=0.858)$, TPC and vanillic acid $(r=0.822)$, protocatechuic acid-and chlorogenic acid $(r=0.807)$ and TFC-vanillic acid $(r=0.784)$, while total phenolic content exhibited a strong relationship with hydro-PSC $(r=0.675)$. These results were consistent with previous studies [45] and indicated that phenolic compounds contribute significantly to the antioxidant capacity. An inverse relationship between the consumption of foods rich in phenolic acids, such as chlorogenic acid and gallic acid, and the occurrence of different diseases has been suggested previously [25]. However, we observed significant correlations between phenolic acids and antioxidant activity in mango cultivars. Our data revealed that mango peel in particular is an excellent source of phenolic compounds, which are major source of natural antioxidants [25]. These findings are in agreement with the declaration that the antioxidant capacity of fruits and vegetables appears to be largely influenced by non-vitamin C phytochemicals [46].

\section{Materials and Methods}

\subsection{Chemicals and Material}

Ascorbic acid (ASA), aluminum chloride, chloranil, tetrahydrofuran (THF), catechin hydrate, vanillin, Folin-Ciocalteu reagent, dichlorofluorescein diacetate (DCFH-DA), 2,2'-azobis-amidinopropane (ABAP), gallic acid and 6-hydroxy-2,5,7,8-tetramethylchroman-2-carboxylic acid (Trolox) were purchased from Sigma Chemical Co. (St. Louis, MO, USA). Potassium dihydrogen phosphate $\left(\mathrm{KH}_{2} \mathrm{PO}_{4}\right)$, sodium borohydride $\left(\mathrm{NaBH}_{4}\right)$, ethanol, acetone, acetic acid, hydrochloric acid $(\mathrm{HCl})$, di-potassium hydrogen phosphate $\left(\mathrm{K}_{2} \mathrm{HPO}_{4}\right)$, sodium carbonate, sodium bicarbonate $\left(\mathrm{NaHCO}_{3}\right)$ and acetonitrile were purchased from Aladdin Co. (Shanghai, China). Protocatechuic acid, chlorogenic acid, (+)-catechin, caffeic acid, $p$-coumaric acid, ferulic acid and formic acid of HPLC grade were purchased from Sigma-Aldrich, Inc. (St. Louis, MO, USA). Methanol and acetonitrile of HPLC grade were purchased from Anpel Scientific instrument Co., Ltd. (Shanghai, China).

Fresh and fully-ripened mango fruits of nine different cultivars, including Luzon (Lvsong), Narcissus (Shuixian), Royal (Guifei), Big Tainong (Da Tainong), Keitt (Kaite), Australian mango (Aozhou), Thai mango (Xiangya), Small Tainong (Xiao Tainong) and Egg mango (Jidan), were purchased from the supermarkets of Guangzhou city in Guangdong province of China and transported instantly to the laboratory for analysis (Figure 4). All fruits were properly cleaned with de-ionized water and stored at $-40{ }^{\circ} \mathrm{C}$ until analysis. 

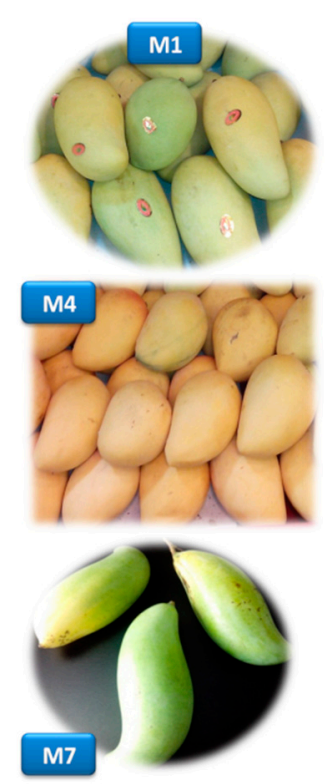

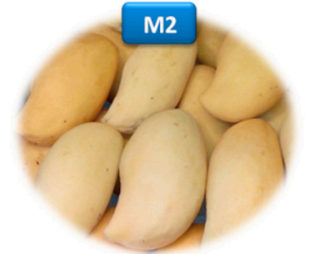

\section{M5}

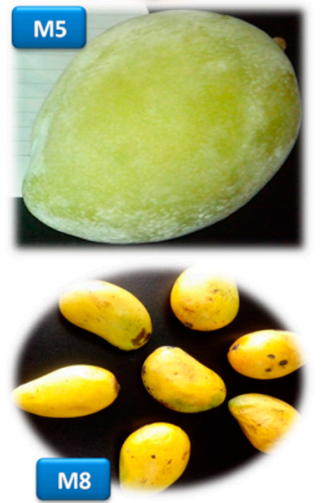

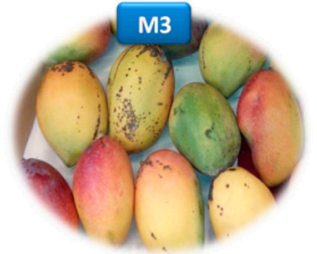

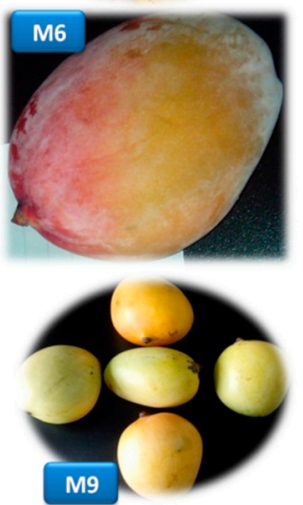

Figure 4. Mango cultivars used in the present analysis. M1, Luzon mango (Lvsong); M2, Narcissus mango (Shuixian); M3, Royal mango (Guifei); M4, Big Tainong mango (Da Tainang); M5, Keitt mango (Kaite); M6, Australian mango (Aozhou); M7, Thai mango (Xiangya); M8, Small Tainong mango (Xiao Tainang); M9, Egg mango (Jidan).

\subsection{Moisture Content}

The moisture content in the pulp and peel was determined by a modified oven-dried method [46]. Briefly, $10 \mathrm{~g}$ of pulp and $5 \mathrm{~g}$ of peel samples were dried in an oven at $105^{\circ} \mathrm{C}$ until constant weight. Each drying test was performed in triplicate, and data were presented as the mean \pm standard deviation (SD) of triplicates.

\subsection{Extraction}

Phenolics were extracted following the method as described by [47], with modifications [48]. Briefly, $5 \mathrm{~g}$ of fresh pulp and $3 \mathrm{~g}$ of fresh peel in triplicate were blended five times each with $25 \mathrm{~mL}$ of $80 \%$ chilled acetone for $5 \mathrm{~min}$, followed by homogenization for $5 \mathrm{~min}$ in an electric homogenizer. Homogenates were centrifuged at $2500 \mathrm{rpm}$ for $10 \mathrm{~min}$; supernatants were pooled in rotary flasks and evaporated using a rotary evaporator at $45^{\circ} \mathrm{C}$ until $10 \%$ of the filtrate was left behind. The filtrates were reconstituted with water to a final volume of $10 \mathrm{~mL}$ and stored at $-40{ }^{\circ} \mathrm{C}$ for further analysis.

\subsection{Determination of Total Phenolic Content}

The Folin-Ciocalteu colorimetric method, as described earlier [49], with modifications [50], was used to determine the total phenolic content in the peel and pulp samples. All extracts were diluted with Milli-Q water to get readings falling within the range of the standard curve concentration: $0.0-600.0 \mu \mathrm{g}$ gallic acid $/ \mathrm{mL}$. One hundred microliters of gallic acid solution or extracts were added to $0.4 \mathrm{~mL}$ of Milli-Q water in each test tube, followed by the addition of Folin-Ciocalteu reagent $(0.1 \mathrm{~mL})$. The solutions were allowed to react for $6 \mathrm{~min}$ to ensure the complete and speedy reaction of the Folin-Ciocalteu reagent with oxidizable phenolates in the sample. Then, $1 \mathrm{~mL}$ of $7 \%$ sodium carbonate 
solution was added to neutralize the mixture, followed by the addition of $0.8 \mathrm{~mL}$ Milli-Q water to adjust the final volume to $2.4 \mathrm{~mL}$. The samples were mixed and allowed to stand for $90 \mathrm{~min}$ at room temperature. After color development, absorbance was measured at $760 \mathrm{~nm}$ on a DU 730 Nucleic Acid/Protein analyzer (BECKMAN, Inc., Fullerton, CA, USA). Total phenolic contents were calculated based on the standard curve of known gallic acid concentrations, and final values were expressed as milligrams of gallic acid equivalent per 100 grams on a fresh weight basis (mg GAE/100 g FW). Data were presented as the mean $\pm \mathrm{SD}$ for triplicates analyses.

\subsection{Estimation of Total Flavonoid Content}

Total flavonoid content was estimated by the sodium borohydride/chloranil method (SBCM) as established in our laboratory [30]. Briefly, $1 \mathrm{~mL}$ of each extract was added into test tubes $(15 \times 150 \mathrm{~mm})$, then kept under nitrogen gas until dried and reconstituted with $1 \mathrm{~mL}$ of tetrahydrofuran/ ethanol (THF/EtOH, 1:1, v/v). Freshly-prepared catechin hydrate $(0.3-10.0 \mathrm{mM})$ in $1 \mathrm{~mL}$ of THF/EtOH $(1: 1, v / v)$ was used as the standard for analysis. Zero-point-five milliliters of each $\left(\mathrm{NaBH}_{4}(50 \mathrm{mM})\right.$ and $\left.\mathrm{AlCl}_{3}(74.6 \mathrm{mM})\right)$ solution were added into all test tubes with samples or standards and shaken on an orbital shaker at room temperature for $30 \mathrm{~min}$. Additionally, $0.5 \mathrm{~mL}$ of $\mathrm{NaBH}_{4}(50.0 \mathrm{mM})$ solution were added into each test tube and shaken for another $30 \mathrm{~min}$ under the same condition. After shaking, $2.0 \mathrm{~mL}$ of chilled acetic acid $(0.8 \mathrm{M})$ were thoroughly mixed, and the mixture was kept in the dark for $15 \mathrm{~min}$. Then, $1 \mathrm{~mL}$ chloranil solution $(20.0 \mathrm{mM})$ was added in each tube, and the mixture was heated at $95{ }^{\circ} \mathrm{C}$ in a shaking bath for $60 \mathrm{~min}$. The reaction solutions were cooled with tap water, and the final volume was kept at $4 \mathrm{~mL}$ using methanol. One milliliter of $16 \%$ vanillin solution $(w / v)$ was added into each tube, followed by the addition of $2 \mathrm{~mL} \mathrm{HCl}(12 \mathrm{M})$, then mixed thoroughly and kept in the dark for $15 \mathrm{~min}$. The reaction solutions were centrifuged at $2500 \mathrm{rpm}$ for $10 \mathrm{~min}$, and absorbance was immediately measured at $490 \mathrm{~nm}$ against a blank using a DU 730 Nucleic Acid/Protein analyzer (BECKMAN, Inc.). Total flavonoid content in each sample was calculated, using the standard curve of catechin hydrate concentration. The final value was expressed as milligrams of catechin equivalent per 100 gram of fresh weight (mg CE/100 $\mathrm{g} \mathrm{FW})$, and data were reported as the mean $\pm \mathrm{SD}$ for triplicate analyses.

\subsection{Determination of Total Anthocyanin Content}

Total anthocyanin content was determined following the method as explained by [41]. Acetone extracts of pulp and peel samples in triplicate were mixed carefully with $0.025 \mathrm{M}$ potassium chloride buffer $(\mathrm{pH}=1)$ in 1:6 ratio. The absorbance was measured at 515 and $700 \mathrm{~nm}$ against distilled water blank (BECKMAN). Afterword, the extracts were mixed with sodium acetate buffer $(\mathrm{pH}=4.5)$; absorbance was measured at the same wavelengths, and the total content of anthocyanins was calculated using the formula as follows:

Total anthocyanins $(\mathrm{mg} / 100 \mathrm{~g}$ of $\mathrm{FW}$ of samples $)=A \times M \mathrm{~W} \times 1000 /(\varepsilon \times C)$

where $A$ is absorbance $=(A 515-A 700) \mathrm{pH} 1.0-(A 515-A 700) \mathrm{pH} 4.5 ; M \mathrm{w}$ is the molecular weight for cyanidin 3-glucoside $=449.2$; $\varepsilon$ is the molar absorptivity of cyanidin 3 -glucoside $=26,900$; and $C$ is the concentration of the buffer in $\mathrm{mg} / \mathrm{mL}$. Anthocyanin content was expressed as milligrams of cyanidin 
3-glucoside equivalent per $100 \mathrm{~g}$ on fresh weight basis (mg CGE/100 $\mathrm{g} \mathrm{FW}$ ), and data were reported as the mean \pm SD for triplicates analyses.

\subsection{Identification and Quantification of Phenolic Acids}

Phenolic acids in the pulp and peel extracts of mango cultivars were determined by the method explained by [15]. Samples were injected automatically into an HPLC system (Waters Corp., Milford, MA, USA) equipped with a photodiode array detector. Absorption spectra for the main peaks were recorded at 280 and $320 \mathrm{~nm}$. The HPLC system was equipped with a C18 reverse phase column ( $250 \mathrm{~mm} \times 4.6 \mathrm{~mm}, 5 \mu \mathrm{m}$ ); the mobile phase was composed of $1 \%$ formic acid (A) and acetonitrile (B), and the isocratic elution gradient was $20 \%$ (B) in $40 \mathrm{~min}$ at a flow rate of $0.6 \mathrm{~mL} / \mathrm{min}$ at $25{ }^{\circ} \mathrm{C}$. The injection volume of the sample was $20 \mu \mathrm{L}$. Peaks were identified on the basis of retention time and chromatographs of the standards. Phenolic acids were identified and quantified on the basis of calibration curves and were expressed as mg phenolics per $100 \mathrm{~g}$ of FW. Data were reported as the mean \pm SD for triplicate analyses.

\subsection{Antioxidant Capacity Assays}

Currently, researchers are paying more attention to natural antioxidants present in fruits, vegetables and whole foods because of their safety and potential nutritional and therapeutic effects [51]. The antioxidant potential of commonly-consumed tropical and subtropical fruit has been rated in the order of guava $>$ mango $>$ papaya $>$ lemon [52]. Owing to the complex reactivity of phytochemicals, the antioxidant capacity of food and food extracts cannot be estimated by only a single method. However, at least two test systems have been recommended to establish legitimacy [53]. Consequently, the antioxidant capacity in the peel and pulp samples of mango cultivars was evaluated by the peroxyl scavenging capacity (PSC) and oxygen radical antioxidant capacity (ORAC) methods.

\subsubsection{Hydrophilic Peroxyl Radical Scavenging Capacity Assay}

The peroxyl scavenging capacity (PSC) assay is based on the oxidation of DCFH by peroxyl radicals and is used to determine the antioxidant capacity in hydrophilic and lipophilic extracts of fruits, vegetables, grains and whole food [47].The hydrophilic peroxyl radical scavenging capacity (hydro-PSC) assay, as explained by [47], with modifications [48,54], was used to assess antioxidant capacity in the pulp and peel of mango cultivars. Seventy five millimolar phosphate buffer (pH 7.4) was used to dilute samples in appropriate concentrations. Ascorbic acid and gallic acid were made fresh and diluted to $(6.3,4.8,3.2,2.4,1.0)$ and $(5,3.5,2.7,1.4,0.9) \mu \mathrm{g} / \mathrm{mL}$ concentrations, respectively, using phosphate buffer (75 mM, pH 7.4). The reaction mixture contained phosphate buffer (75 mM, $\mathrm{pH} 7.4$ ), ABAP $(40 \mathrm{mM}), \mathrm{DCFH}$ dye $(13.26 \mu \mathrm{M})$ and the suitable amount of the pure antioxidant compound or sample extract. The dye was prehydrolyzed with $1 \mathrm{mM} \mathrm{KOH}$ to eradicate di-acetate before use and the reaction was carried out at $37^{\circ} \mathrm{C}$, in a total volume of $250 \mu \mathrm{L}$ using a 96-well plate. Fluorescence generation was observed (excitation at $485 \mathrm{~nm}$ and emission at $538 \mathrm{~nm}$ ) on a Fluoroskan Ascent fluorescent spectrophotometer (SoftMax systems, Molecular Devices, Sunnyvale, CA, USA). Data were analyzed using SoftMax Pro Software, Version 6.2 (SoftMax systems, Molecular Devices) running on 
a PC. The areas under the fluorescence reaction time kinetic curve (AUC) for both control and samples were included and used as the basis for the determination of peroxyl radical scavenging capacity (PSC) using equation:

$$
P S C(\text { Value })=1-(S A / C A)
$$

where $S A$ is the AUC for the sample or standard dilution and $C A$ is the AUC for the control reaction. Compounds or extracts inhibiting the oxidation of DCFH produced lesser $S A$ and higher PSC values. EC50, the dose requisite to cause $50 \%$ inhibition $(P S C$ unit $=0.5)$ for each pure compound or sample extract, was used to assess antioxidant activity of different compounds or samples. Final values of hydro-PSC were expressed as $\mu \mathrm{mol}$ of vitamin C equivalent per $100 \mathrm{~g}$ of $\mathrm{FW}(\mu \mathrm{M} v \mathrm{ve} / 100 \mathrm{~g}$ of $\mathrm{FW}$ ), and data were reported as the mean $\pm \mathrm{SD}$ of each triplicate.

\subsubsection{Oxygen Radical Scavenging Capacity Assay}

The ORAC assay is a widely-used method to analyze the oxygen radical absorbance capacity of plant species extracts. This assay is based on free radical damage to a fluorescent probe through a change in its fluorescence intensity [55]. In the typical ORAC assay, the fluorescent loss of probes as phycoerythrin or fluorescein is followed over time in the absence and presence of antioxidant [41]. The oxygen radical absorbance capacity (ORAC) assay, as described by [55], with modifications [56], was conducted to measure the total antioxidant activity of the studied samples. Briefly, $20 \mu \mathrm{L}$ of sample extracts in triplicate, diluted with $75 \mathrm{mM}$ phosphate buffer ( $\mathrm{pH} 7.4$ ), were added in 96-well microplate, followed by the addition of $200 \mu \mathrm{L}$ of fluorescein $(0.96 \mu \mathrm{M})$, and incubated at $37^{\circ} \mathrm{C}$ for $20 \mathrm{~min}$. Outer wells were kept empty to avoid variation from inner wells. After incubation, $20 \mu \mathrm{L}$ of freshly-prepared $119.4 \mathrm{mM}$ AAPH in $75 \mathrm{mM}$ phosphate buffer ( $\mathrm{pH}$ 7.4) were added into each well, and the fluorescence intensity was measured immediately for 35 cycles every $4.5 \mathrm{~min}$ at an excitation of $485 \mathrm{~nm}$ and emission of $535 \mathrm{~nm}$ by the FilterMax F5 Multi-Mode Microplate Reader (Molecular Devices, Sunnyvale, CA, USA). Different concentrations of Trolox (range 6.25-50 $\mu \mathrm{M}$ ) were used as a control. ORAC values were calculated by extrapolation on a calibration curve and expressed as the mean $\pm \mathrm{SD}$ micromoles of Trolox equivalent per $100 \mathrm{~g}$ of fresh weigh ( $\mu \mathrm{M}$ TE/100 $\mathrm{g}$ of FW) for three replicates.

\subsection{Statistical Analysis}

Statistical analyses were performed using SPSS software 13.0 (SPSS Inc., Chicago, IL, USA), and the dose effect was analyzed using Calcusyn software Version 2.0 (Biosoft, Cambridge, UK). Results were subjected to ANOVA, and differences among means were located using Tukey's multiple comparison test. A $p$-value less than $0.05(p<0.05)$ was regarded as statistically significant. Basic statistical parameters and correlation coefficients among the measured variables were also calculated. All data were reported as the mean \pm SD for three replicates.

\section{Conclusions}

The present study was focused on comparative assessment of phenolic content and in vitro antioxidant capacity in the pulp and peel of mango cultivars. Though phenolic compounds showed a significant contribution in the inhibition of free radicals, the antioxidant capacity of mango and other fruits is not 
only due to the content of phenolic acids. It may also be due to the presence of various bioactive compounds, such as carotenoids, vitamins and other polyphenolics phytochemicals present in the pulp and peel of mango, which were not identified in the present study. Our results showed that the Xiao Tainang and Aozhou cultivars contained maximum phenolic content and exhibited remarkable antioxidant capacity. Gallic acid and protocatechuic acid were predominant in the peel and pulp of the studied samples. Highly significant correlations ( $r=0.997,0.962,0.922$, etc.) were calculated between phenolic and antioxidant properties, particularly in the peel samples. The present study revealed that the antioxidant capacity of mango peel is due to the synergistic actions of phenolics and other bioactive compounds present in it. Therefore, it is suggest that mango peel may contribute to promoting human health as a functional food or a value-added ingredient. To our knowledge, this is the first report on the comparative assessment of phenolic compounds and antioxidant capacity determined by ORAC and hydro-PSC assays in the peel and pulp of mango cultivars in China, particularly in peel. However, additional studies are desirable to assess the bio-absorption, mechanism of action and associations between these compounds after consumption.

\section{Acknowledgments}

The authors are grateful for the financial support from the China Postdoctoral Science Foundation (2015M572324), the Fundamental Research Funds for the Central Universities (2014 M0072), Science and Technology Planning Project of Guangdong Province (2013B090700008) and the Leading Talents Program in Guangdong Province (Rui Hai Liu).

\section{Author Contributions}

Arshad Mehmood Abbasi and Xinbo Guo designed the experiments. Xiong Fu, Lin Zhou, Youngsheng Chen, Huaifeng Yan and Yong Zhu analyzed data, contributed reagents, materials and analytical tools. Rui Hai Liu supervised the project and provided intellectual, financial and technical support.

\section{Conflicts of Interest}

The authors declare no conflict of interest.

\section{References}

1. Joaquín-Cruz, E.; Dueñas, M., García-Cruz, L.; Salinas-Moreno, Y.; Santos-Buelga, C.; García-Salinas, C. Anthocyanin and phenolic characterization, chemical composition and antioxidant activity of chagalapoli (Ardisiacompressa K.) fruit: A tropical source of natural pigments. Food Res. Int. 2015, 70, 151-157.

2. Liu, M.; Li, X.Q.; Weber, C.; Lee, C.Y.; Brown, J.; Liu, R.H. Antioxidant and antiproliferative activities of raspberries. J. Agric. Food Chem. 2002, 50, 2926-2930.

3. Souza, V.; Pereira, P.; Queiroz, F.; Borges, S.; Carneiro, J. Determination of bioactive compounds, antioxidant activity and chemical composition of Cerrado Brazilian fruits. Food Chem. 2012, 134, 381-386. 
4. Dina, A.; Nassima, C.; Meriem, B.; Karima, A.; Hakima, L.; Hania, B. Antioxidant capacity and phenol content of selected Algerian medicinal plants. Food Chem. 2009, 112, 303-309.

5. Fu, L.; Xu, B.T.; Xu, X.R.; Gan, R.Y.; Zhang, Y.; Xia, E.Q.; Li, H.B. Antioxidant capacities and total phenolic contents of 62 fruits. Food Chem. 2011, 129, 345-350.

6. Hervert-Hernández, D.; García, O.P.; Rosado, J.L.; Goñi, I. The contribution of fruits and vegetables to dietary intake of polyphenols and antioxidant capacity in a Mexican rural diet: Importance of fruit and vegetable variety. Food. Res. Int. 2011, 44, 1182-1189.

7. Podsedek, A. Natural antioxidants and antioxidant capacity of Brassica vegetables: A review. LWT Food Sci. Technol. 2007, 40, 1-11.

8. Rehman, M.M.; Khiyanagi, T.; Komiyana, T.; Sato, S.; Konishi, T. Effect of anthocyanins on psychologcal stress-induced oxidative stress and neuro-transmitter status. J. Agric. Food Chem. 2008, 56, 7545-7550.

9. Liu, R.H. Health benefits of fruit and vegetables are from additive and synergistic combinations of phytochemicals. Am. J. Clin. Nutr. 2003, 78, 517S-520S.

10. Masibo, M.; He, Q. Major mango polyphenols and their potential significance to human health. Compr. Rev. Food Sci. Food Saf. 2008, 7, 309-319.

11. Noratto, G.D.; Bertoldi, M.C.; Krenek, K.; Talcott, S.T.; Stringheta, P.C.; Mertens-Talcott, S.U. Anticarcinogenic effects of polyphenolics from mango (Mangifera indica) varieties. J. Agric. Food Chem.2010, 58, 4104-4112.

12. Deng, G.F.; Lin, X.; Xu, X.R.; Gao, L.L.; Xie, J.F.; Li, H.B. Antioxidant capacities and total phenolic contents of 56 vegetables. J. Funct. Foods 2013, 5, 260-266.

13. Soobrattee, M.A.; Neergheen, V.S.; Luximon-Ramma, A.; Aruoma, O.I.; Bahorun, T. Phenolics as potential antioxidant therapeutic agents: Mechanism and actions. Mutat. Res. 2005, 579, 200-213.

14. Robles-Sánchez, R.M.; Rojas-Graü, M.A.; Odriozola-Serrano, I.; González-Aguilar, G.A.; Martín-Belloso, O. Effect of minimal processing on bioactive compounds and antioxidant activity of fresh-cut "Kent" mango (Mangifera indica L.). Postharvest Biol. Technol. 2008, 51, 384-390.

15. Palafox-Carlos, H.; Yahia, E.M.; González-Aguilar, G.A. Identification and quantification of major phenolic compounds from mango (Mangifera indica, cv. Ataulfo) fruit by HPLC-DADMS/MS-ESI and their individual contribution to the antioxidant activity during ripening. Food Chem. 2012, 135, $105-111$.

16. De la Rosa, L.A.; Alvarez-Parrilla, E.; González-Aguilar, G.A. The contribution of fruits and vegetables consumption to human health. In Fruit and Vegetable Phytochemicals: Chemistry, Nutritional and Stability; Yahia, E.M., Ed.;Wiley-Blackwell: Ames, IA, USA, 2010; pp. 3-52.

17. Ji, B.C.; Hsu, W.H.; Yang, J.S.; Hsia, T.C.; Lu, C.C.; Chiang, J.H. Gallic acid induces apoptosis via caspase-3 and mitochondrion-dependent pathways in vitro and suppresses lung xenograft tumor growth in vivo. J. Agric. Food Chem. 2009, 57, 7596-7604.

18. Balasubashini, M.S.; Rukkumani, R.; Menon, V.P. Protective effects of ferulic acid on hyperlipidemic diabetic rats. Acta Diabetol. 2003, 40, 118-122.

19. Graf, E. Antioxidant potential of ferulic acid. Free Radic. Biol. Med. 1992, 13, 435-448.

20. Farah, A.; Monteiro, M.; Donangelo, C.M.; Lafay, S. Chlorogenic acids from green coffee extract are highly bioavailable in humans. J. Nutr. 2008, 138, 2309-2315. 
21. Tseng, T.H.; Kao, T.W.; Chu, C. Y.; Chou, F.P.; Lin, W.L.; Wang, C.J. Induction of apoptosis by hibiscus protocatechuic acid in human leukemia cells via reduction of retinoblastoma (RB) phosphorylation and Bcl-2 expression. Biochem. Pharmacol. 2000, 60, 307-315.

22. Osman, H.F. Health aspects of caffeic acid and Berries juice in improvement of hypertension symptoms induced by deoxcorticosterone acetate on male rats. Int. J. Med. Med. Sci. 2014, 47, 1437-1443.

23. Gao, A.; Chen, Y.; Crane, J.H.; Zhu, M.; Huang, J.; Luo, H. Status and analysis on Mango production in China. Adv. Biomed. Eng. 2011, 12, 472-476.

24. Ramirez, J.E.; Zambrano, R.; Sepúlveda, B.; Simirgiotis, M.J. Antioxidant properties and hyphenated HPLC-PDA-MS profiling of chilean Pica mango fruits (Mangifera indica L. cv. piqueño). Molecule 2014, 19, 438-458.

25. Ma, X.; Wu, H.; Liu, L.; Yao, Q.; Wang, S.; Zhan, R.; Xing, S.; Zhou, Y. Polyphenolic compounds and antioxidant properties in mango fruits. Sci. Hortic. 2011, 129, 102-107.

26. Siddiq, M.; Sogi, D.S.; Dolan, K.D. Antioxidant properties, total phenolics, and quality of fresh-cut "Tommy Atkins" mangoes as affected by different pre-treatments. LWT Food Sci. Technol. 2013, 53, 156-162.

27. Sogi, D.S.; Siddiq, M.; Greiby, I.; Dolan, K.D. Total phenolics, antioxidant activity, and functional properties of "Tommy Atkins" mango peel and kernel as affected by drying methods. Food Chem. 2013, 141, 2649-2655.

28. Ajila, C.M.; Bhat, S.G.; Prasada Rao, U.J.S. Valuable components of raw and ripe peels from two Indian mango varieties. Food Chem. 2007, 102, 1006-1011.

29. Luthria, D.L. Optimization of extraction of phenolic acids from a vegetable waste product using a pressurized liquid extractor. J. Funct. Foods 2012, 4, 842-850.

30. Wolfe, K.; Wu, X.; Liu, R.H. Antioxidant activity of apple peels. J. Agric. Food Chem. 2003, 51, 609-614.

31. Ajila, C.M.; Rao, P. Mango peel dietary fibre: Composition and associated bound phenolics. J. Funct. Foods 2013, 5, 444-450.

32. Ajila, C.M.; Naidu, K.A.; Bhat, S.G.; Prasada Rao, U.J.S. Bioactive compounds and antioxidant potential of mango peel extract. Food Chem. 2007, 105, 982-988.

33. Kim, H.; Moon, J.Y.; Kim, H.; Lee, D.; Cho, M.; Choi, H.; Kim, Y.S.; Mosaddik, A.; Cho, S.K. Antioxidant and antiproliferative activities of mango (Mangiferaindica L.) flesh and peel. Food Chem. 2010, 121, 429-436.

34. Almeida, M.B.; Sousa, P.H.; Arriaga, A.M.; Prado, G.M.; Magalhães, C.E.; Maia, G.A. Bioactive compounds and antioxidant activity of fresh exotic fruits from northeastern Brazil. Food Res. Int. 2011, 44, 2155-2159.

35. Ueda, M.; Sasaki, K.S.; Utsunimiya, N.; Inaba, K.; Bayashi, Y.S. Variation of total polyphenol and polyphenol oxidase activity during maturation of mango fruit (MangiferaIndica L. Irwin) cultured in plastic green house. Food Sci. Technol. Res. 2000, 6, 299-305.

36. Shieber, A.; Ulrich, W.; Carle, R. Characterization of polyphenols in mango puree concentrate by HPLC with diode array and mass spectrometric detection. Innov. Food Sci. Emerg. Technol. 2000, $1,161-166$. 
37. Manthey, J.A.; Perkins-Veazie, P. Influences of harvest date and location on the levels of $\beta$-carotene, ascorbic acid, total phenols, the in vitro antioxidant capacity, and phenolic profiles of five commercial varieties of mango (Mangifera indica L.). J. Agric. Food Chem. 2009, 57, 10825-10830.

38. Huang, L.K.; Jiang, X.Y.; Huang, Q.T.; Xiao, Y.F.; Chen, Z.H; Zhang, X.Q.; Miao, J.M.; Yan, H.D. Genetic diversity and relationships in cultivars of Loliummultiflorum Lam. using sequence-related amplified polymorphism markers. Genet. Mol. Res. 2014, 13, 10142-10149.

39. Simirgiotis, M.J.; Theoduloz, C.; Caligari, P.D.S.; Schmeda-Hirschmann, G. Comparison of phenolic composition and antioxidant properties of two native Chilean and one domestic strawberry genotypes. Food Chem. 2009, 113, 377-385.

40. Robles-Sánchez, R.M.; Islas-Osuna, M.A.; Astiazarán-García, H.; Vázquez-Ortiz, F.A.; Martín-Belloso, O.; Gorinstein, S. Quality index, consumer acceptability, bioactive compounds, and antioxidant activity of fresh cut "Ataulfo" mangoes (Mangiferaindica L.) as affected by low temperature storage. J. Food Sci. 2009, 74, S126-S134.

41. He, X.; Liu, D.; Liu, R.H. Sodium borohydride/chloranil-based assay for quantifying total flavonoids. J. Agric. Food Chem. 2008, 56, 9337-9344.

42. Scalzo, J.; Politi, A.; Pellegrini, N.; Mezzetti, B.; Battino, M. Plant genotype affects total antioxidant capacity and phenolic contents in fruit. Nutrition 2005, 21, 207-213.

43. Meyers, K.; Watkins, C.; Pritts, M.; Liu, R.H. Antioxidant and antiproliferative activities of strawberries. J. Agric. Food Chem. 2003, 51, 6887-6892.

44. Roesler, R.; Malta, L.G.; Carrasco, L.C.; Pastore, G. Evaluation of antioxidant properties of the Brazilian Cerrado fruit Annona crassiflora (Araticum). Food. Chem. Toxicol. 2006, 71, $102-107$.

45. Zhou, K.; Hao, J.; Griffey, C.; Chung, H.; O’Keefe, S.F.; Chen, J. Antioxidant properties of Fusarium head blight-resistant and -susceptible soft red winter wheat grains grown in Virginia. J. Agric. Food Chem. 2007, 55, 3729-3736.

46. Prior, R.L.; Cao, G.H.; Martin, A.; Sofic, E.; McEwen, J.; O’Brien, C. Antioxidant capacity as influenced by total phenolic and anthocyanin content, maturity, and variety of Vaccinium species. J. Agric. Food Chem. 1998, 46, 2686-2693.

47. Adom, K.K.; Liu, R.H. Rapid peroxyl radical scavenging capacity (PSC) assay for assessing both hydrophilic and lipophilic antioxidants. J. Agric. Food Chem. 2005, 53, 6572-6580.

48. Guo, X.B.; Li, T.; Tang, K.X.; Liu, R.H. Effect of germination on phytochemical profiles and antioxidant activity of mung bean sprouts (Vignara diata). J. Agric. Food Chem. 2012, 60, 11050-11055.

49. Singleton, V.L.; Orthofer, R.; Lamuela-Raventos, R.M. Analysis of total phenols and other oxidation substrates and antioxidants by means of Folin-Ciocalteu reagent. Methods Enzymol. 1999, 299, 152-178.

50. Song, W.; Derito, C.M.; Liu, M.K.; He, X.J.; Dong, M.; Liu, R.H. Cellular antioxidant activity of common vegetables. J. Agric. Food Chem. 2010, 58, 6621-6629.

51. Rufino, M.; Fernandes, F.; Alves, R.; Brito, E. Free radical-scavenging behavior of some north-east Brazilian fruits in a DPH system. Food Chem. 2009, 114, 693-695.

52. Torunn, S.; Siv, F.R.; Kare, A.L. Total antioxidant activity in 35 Ugandan fruits and vegetables. Food Chem. 2009, 113, 85-91. 
53. Tenore, G.C.; Novellino, E.; Basile, A. Nutraceutical potential and antioxidant benefits of red pitaya (Hylocereus polyrhizus) extracts. J. Funct. Foods 2012, 4, 129-136.

54. Chen, Y.; Wang, G.; Wang, H.; Cheng, C.; Zang, G.; Guo, X.; Liu, R.H. Phytochemical profiles and antioxidant activities in six species of Ramie leaves. PLOS ONE 2014, 9, e108140.

55. Huang, D.J.; Ou, B.X.; Hampsch-Woodill, M.; Flanagan, J.A.; Prior, R.L. High-throughput assay of oxygen radical absorbance capacity (ORAC) using a multichannel liquid handling system coupled with a microplate flourescence reader in 96-well format. J. Agric. Food Chem. 2002, 50, 4437-4444.

56. Zhang, M.W.; Zhang, R.F.; Zhang, F.X.;Liu, R.H. Phenolic profiles and antioxidant activity of black rice bran of different commercially available varieties. J. Agric. Food Chem. 2010, 58, $7580-7587$.

(C) 2015 by the authors; licensee MDPI, Basel, Switzerland. This article is an open access article distributed under the terms and conditions of the Creative Commons Attribution license (http://creativecommons.org/licenses/by/4.0/). 